\title{
Early catastrophic acetabular failure in Furlong total hip replacements
}

\author{
David Knox $\cdot$ Steven W. Hamilton • \\ Douglas Wardlaw $\cdot$ Peter H. Gibson
}

Received: 14 July 2008/Accepted: 28 December 2008/Published online: 31 January 2009

(C) Springer-Verlag 2009

\begin{abstract}
The use of uncemented hip arthroplasty prostheses with ceramic articulations are popular, especially in the young, because of a perceived reduction in wear. We highlight a complication of ceramic on polyethylene articulating couples not previously described in the Furlong replacement. Despite widespread metalosis and particulate debris, osteolysis was not initially seen. The contamination compromised subsequent revision.
\end{abstract}

Keywords Ceramic on polyethylene articulation . Furlong replacement $\cdot$ Acetabular failure

\section{Introduction}

We present two cases of early and catastrophic acetabular failure in the uncemented Furlong total hip replacement (JRI, London, UK). The Furlong has produced some encouraging results, but we would like to sound a note of caution if using a ceramic on polyethylene articulating couple. The patients have provided consent to the publication of their clinical reports.

\section{Case report}

A female patient, aged 51, underwent a right total hip replacement for osteoarthritis. An uncemented, HA-coated, Furlong modular replacement was inserted with a $28 \mathrm{~mm}$ ceramic head and press-fit Furlong cup. A polyethylene

D. Knox $(\bowtie) \cdot$ S. W. Hamilton · D. Wardlaw · P. H. Gibson Department of Orthopaedic Surgery, Woodend Hospital, Eday Road, Aberdeen AB15 6LS, Scotland, UK e-mail: davidknox@ doctors.org.uk insert of $10 \mathrm{~mm}$ thickness was used. This was successful and she returned to work as a secretary, reporting no limitation of activity.

Seven years later she presented to her family doctor complaining of a recurrence of right hip pain. An X-ray was performed and was reported as normal. Her pain persisted and a repeat X-ray was again reported as normal. She was reviewed in our institution 21 months after her recurrence of pain. Examination revealed a good range of movement in all planes, but there was gross audible crepitus. The right leg was shorter than the left. A comparison of the X-ray films is shown in Fig. 1a and b.

There were no radiolucencies and no measurable migration of either component was present. There was no osteolysis. On the later film there was very evident failure of the polyethylene liner and migration of the ceramic head.

At revision the femur was found to be solidly fixed. Tissues surrounding the acetabulum were heavily stained with black metalosis. The femoral head had eroded through the polyethylene liner and continued through the roof of the titanium acetabular component to rest on the acetabular bone (Fig. 2). The acetabular prosthesis, despite this, remained securely fixed. There was no suggestion of infection and no abnormality in the original positioning of the components. The acetabular component was revised to a similar $52 \mathrm{~mm}$ HA-coated CSF Furlong cup secured with four cancellous screws. The head was replaced with a $28 \mathrm{~mm}$ cobalt chrome Furlong head. This patient recently required further acetabular revision 11 years post initial primary arthroplasty. On this occasion, the acetabulum was exchanged for a cemented Ogee (De Puy, Leeds, UK) cup due to persistant pain and evidence of acetabular aseptic loosening. Again the femoral component was solidly fixed at operation and left in situ. According to the images in 

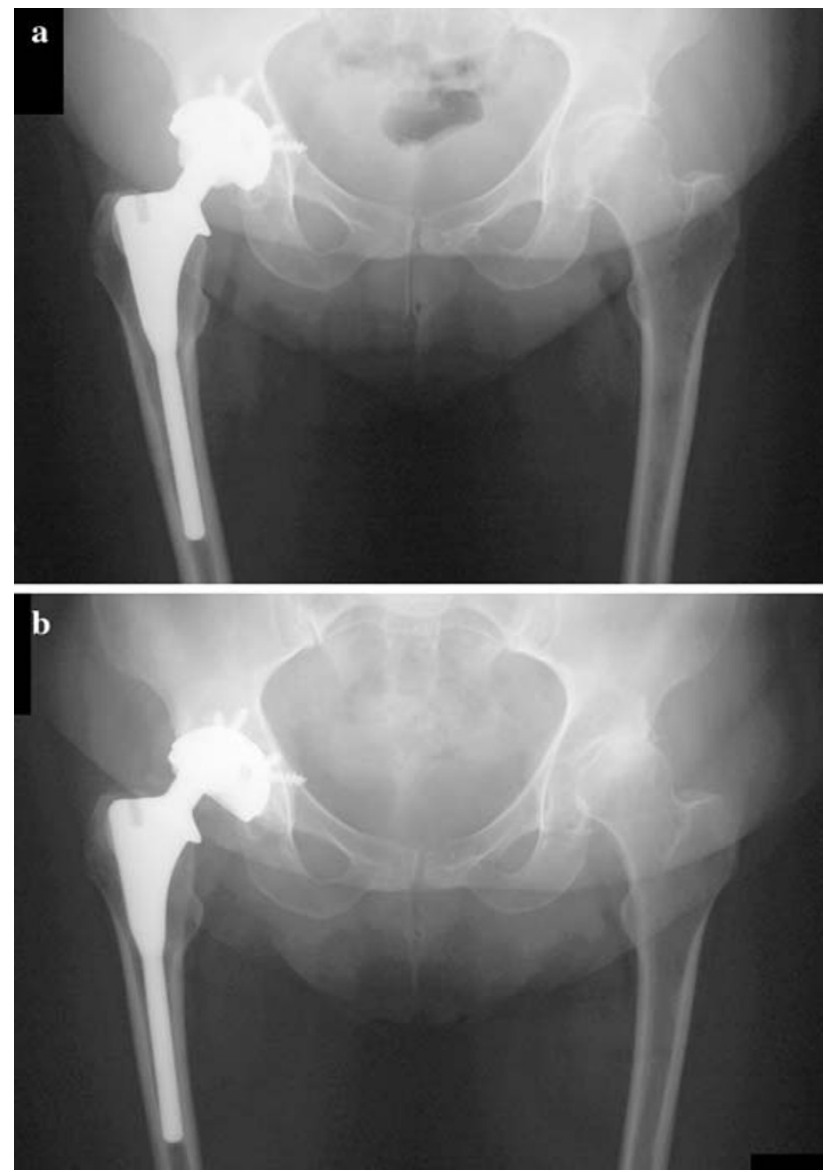

Fig. 1 Comparison of AP X-rays performed two years apart after recurrence of symptoms

Figs. 3 and 4, there was evident resorption of the femoral calcar, but this does not appear to have adversely affected femoral stability.

In a similar case, a 58-year-old lady was referred to our clinic complaining of left hip symptoms three years after having undergone bilateral uncemented Furlong replacements for primary hip osteoarthritis. Hydroxyapatitecoated, titanium-threaded cups with $8 \mathrm{~mm}$ polyethylene inserts were fitted on the acetabular side and alumina ceramic heads were used in an effort to minimise wear. She made a good recovery and returned to work as a teacher but was urgently referred due to gradually increasing pain in the left groin and an audible squeak. X-rays showed no evidence of acetabular or femoral stem loosening; however, the femoral head lay eccentric in the polyethylene insert (Fig 5).

During revision there was moderate metalosis and staining of the tissues. The acetabular and femoral components were solidly fixed in position; however, the ceramic head had eroded through both the lip of the polyethylene liner and the lateral rim of the titanium cup

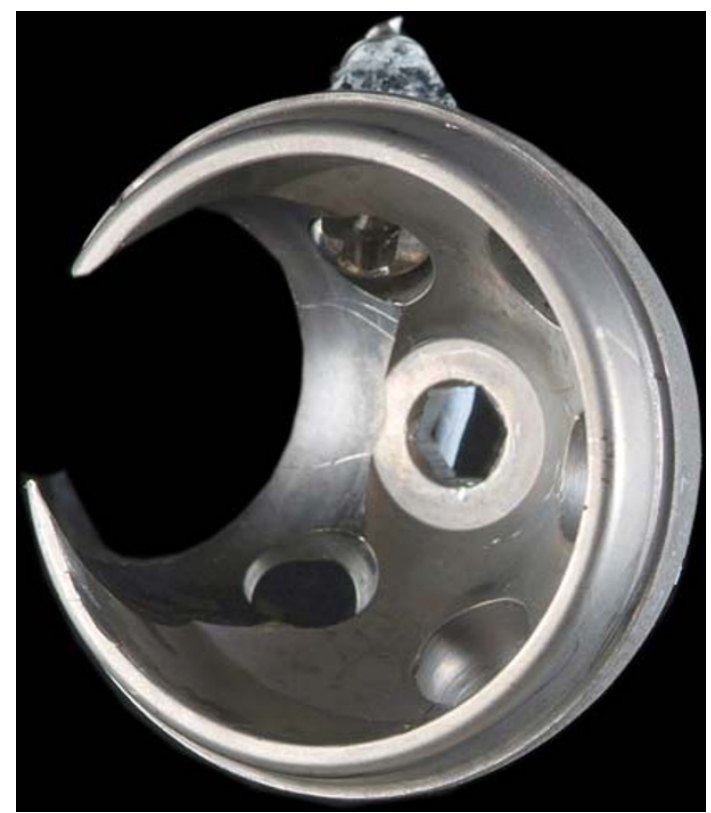

Fig. 2 The ceramic femoral head had eroded through the polyethylene liner and metal acetabular component. The heads of the cancellous fixation screws were also worn

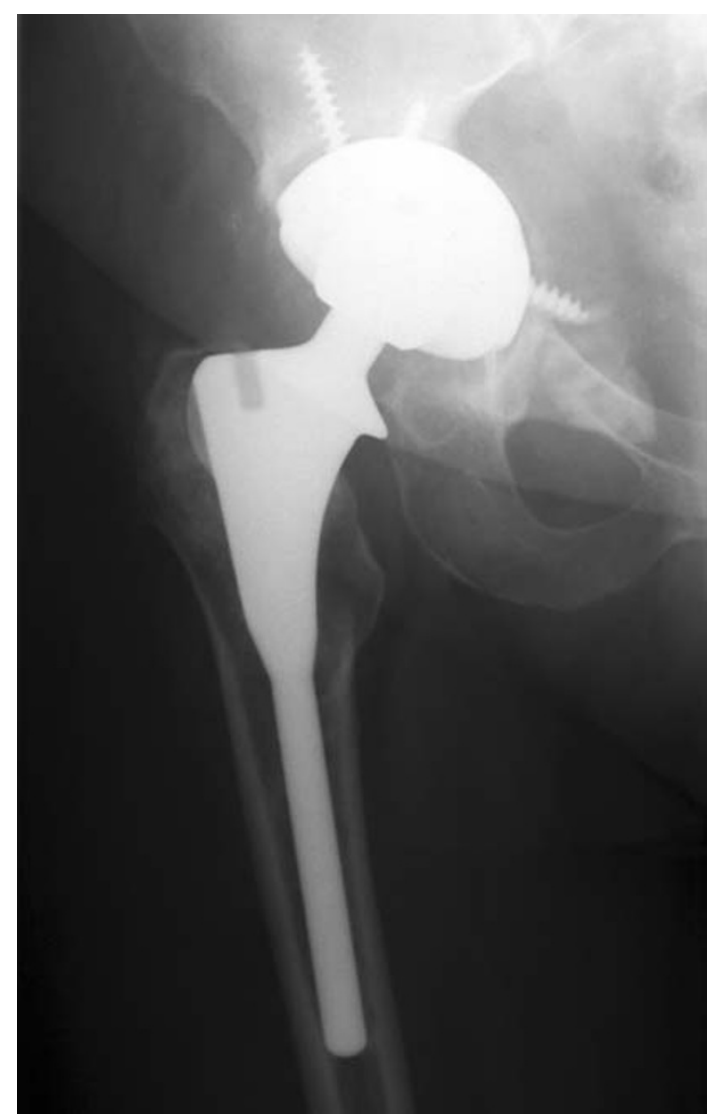

Fig. 3 Appearance 11 years post primary replacement and two years post acetabular revision. Failure of acetabular integration is evident 


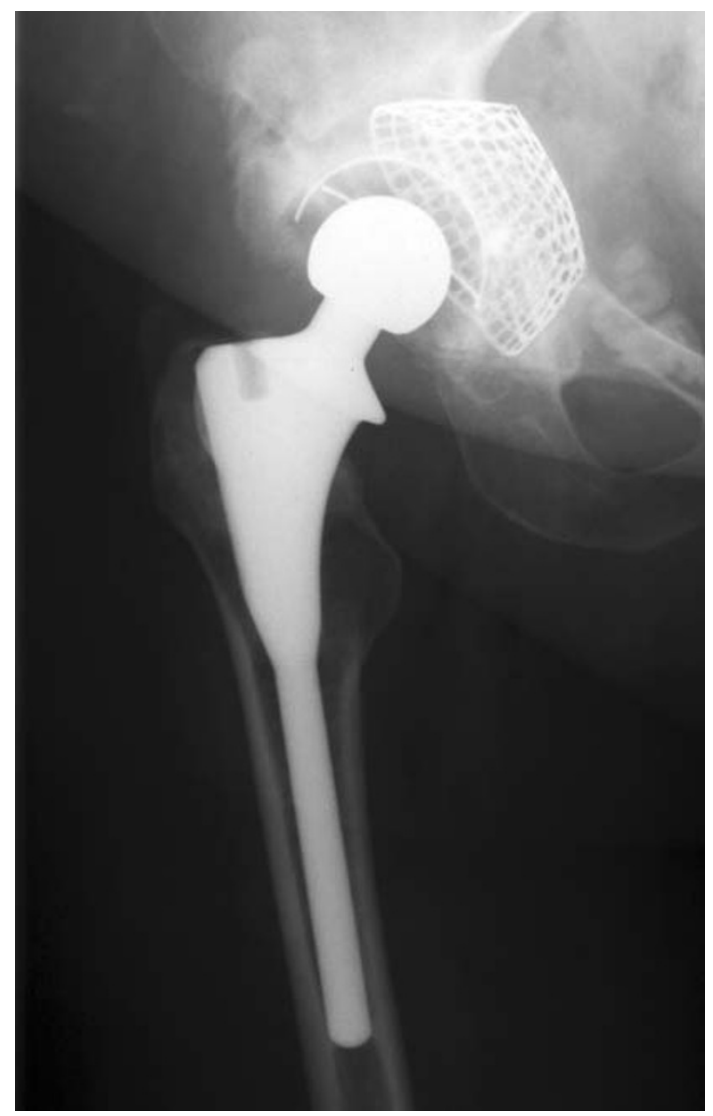

Fig. 4 Two months post cemented acetabular revision. The femoral component remains solidly fixed despite calcar resorption

(Fig. 6). There was no evidence of infection or prosthesis loosening. Again this was revised to a similar uncemented Furlong HA-coated acetabular component, and the patient initially appeared to make a good recovery.

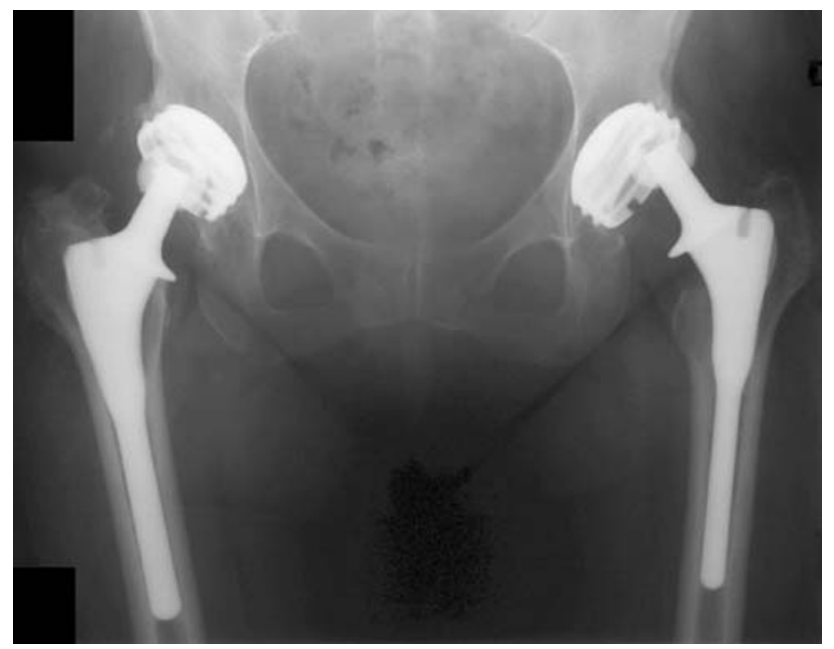

Fig. 5 X-ray appearance three years post replacement

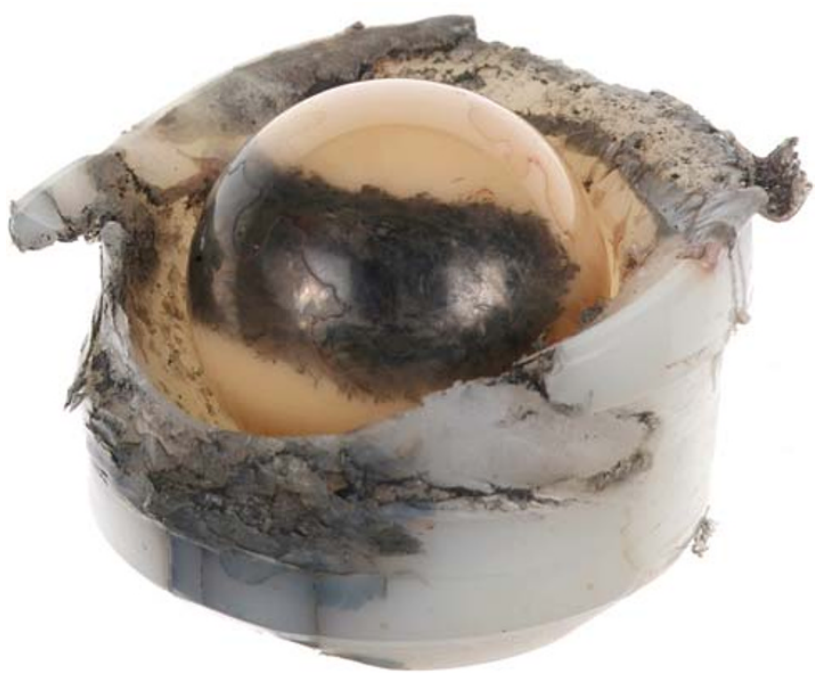

Fig. 6 Erosion of the polyethylene liner and resulting metalosis and staining

\section{Discussion}

These cases illustrate dramatic abrasion of the polyethylene, cancellous screws and metal acetabulum. In the first example, this occurred in the presence of no apparent prosthesis malpositioning; however, in the later case, a rather steep cup inclination with a cup abduction angle of $52^{\circ}$ may have played a contributing role. Neither case showed evidence of defective implant manufacture, nor were there initial radiographic signs of osteolysis, migration or loosening. All components were found to be solidly fixed at the time of revision and the femoral components were left in situ.

The Furlong hip replacement is an uncemented, fully hydroxyapatite-coated arthroplasty system that has attracted attention due to encouraging reported survival [1-3]. McNally, at a mean follow-up of ten years, found a $97 \%$ survival for the acetabular component and 99\% for the femoral stem. At 13-15 years, Shetty reported $99 \%$ replacement survival, and Tindall et al. also describe $99 \%$ survival of the cup at 13 years. Other authors have specifically recommended its use in the young replacement patient, reporting positive results in those aged between 21 and 55 years [4-6]. Robertson described a ten-year stem survival of 95 and $98 \%$ for the acetabular side. There is one note of caution, however, with Sharma reporting disappointing acetabular survival. In 77 cases, 17 cups were revised within seven years. All were revised for aseptic loosening; none showed signs of excessive polyethylene wear. He reported a cup survival of $79 \%$ [7].

We report catastrophic failure of the polyethylene acetabular liner in active patients who became symptomatic in the early to intermediate time frame post replacement. This 
is of particular note due to the initial lack of associated osteolysis and also due to the failure of the titanium shell in conjunction with a ceramic head. Such a failure has not previously been described in the Furlong hip replacement.

Femoral heads in the Furlong system are available in either cobalt chrome or alumina oxide ceramic, and there is a choice of polyethylene or ceramic acetabular liners. The ultrahigh molecular weight polyethylene insert is gamma irradiated in the absence of oxygen and is available in a variety of thicknesses, the minimum of which is $8 \mathrm{~mm}$. There has been an inclination toward the use of ceramics in young, active patients due to their perceived advantages of low friction and chemical inertness. Authors have described a significantly lower polyethylene wear rate when comparing ceramic heads and cobalt chrome $[8,9]$. There is, however, contradictory literature [10, 11]. Needham et al. [12] have also recently described a case of catastrophic failure in a ceramic-polyethylene bearing couple.

If the risk of polyethylene wear is recognised early, with modular prostheses such as the Furlong, it may be possible to replace the affected liner [13]. However, if allowed to progress and affect the acetabulum, one faces the prospect of revising components in a field contaminated with abrasive particulate debris. This occurred in both of these cases, and now both of our patients have undergone or are currently awaiting further acatabular revision.

Conflict of interest statement The authors declare that they have no conflict of interest related to the publication of this article.

\section{References}

1. McNally SA, Shepperd JAN, Mann CV, Walczak JP (2000) The results at nine to twelve years of the use of a hydroxyapatitecoated femoral stem. J Bone Joint Surg Br 82(3):378-382
2. Shetty AA, Slack R, Tindall A, James KD, Rand C (2005) Results of a hydroxyapatite-coated (Furlong) total hip replacement. A 13 to 15 year follow up. J Bone Joint Surg Br 87(8):1050-1054

3. Tindall A, James KD, Slack R, James C, Shetty AA (2007) Longterm follow up of a hydroxyapatite ceramic-coated threaded cup. An analysis of survival and fixation at up to 15 years. J Arthroplasty 22(8):1079-1082

4. Robertson A, Lavalette D, Morgan S, Angus PD (2005) The hydroxyapatite-coated JRI-Furlong hip. Outcome in patients under the age of 55 years. J Bone Joint Surg Br 87(1):12-15

5. Loupasis G, Morris EW, Hyde ID (1998) The Furlong hydroxyapatite-coated total hip replacement in patients under age 51. A 6 year follow up study. Acta Orthop Belg 64(1):17-24

6. Singh S, Trikha SP, Edge AJ (2004) Hydroxyapatite ceramiccoated femoral stems in young patients. A prospective 10 year study. J Bone Joint Surg Br 86(8):1118-1123

7. Sharma DK, Brooks S (2006) Long-term follow up (11 years plus) results of JRI (Furlong) total hip arthroplasty in young patients: cause for concern regarding acetabular cup? Int Orthopaedics 30(5):375-380

8. Kim YH (2005) Comparison of polyethylene wear associated with cobalt chrome and zirconia heads after total hip replacement. J Bone Joint Surg Am 87(8):1769-1776

9. Hamilton WG, Hopper RH Jr, Ginn SD, Hammell NP, Engh CA Jr, Engh CA (2005) The effect of total hip arthroplasty cup design on polyethylene wear rate. J Arthroplasty 20(7 Suppl 3):63-72

10. Sychterz CJ, Engh CA Jr, Young AM, Hopper RH Jr, Engh CA (2000) Comparison of in vivo wear between polyethylene liners articulating with ceramic and cobalt chrome femoral heads. J Bone Joint Surg Br 82(7):948-951

11. Migaud H, Jobin A, Chantelot C, Giraud F, Laffargue P, Duquennoy A (2004) Cementless metal on metal hip arthroplasty in patients less than 50 years of age: comparison with a matched control group using ceramic on polyethylene after a minimum 5 year follow up. J Arthroplasty 19(8 Suppl 3):23-28

12. Needham J, Burns T, Gerlinger T (2008) Catastrophic failure of ceramic-polyethylene bearing total hip arthroplasty. J Arthroplasty 23(4):627-630

13. Wade FA, Rapuri VR, Parvizi J, Hozack WJ (2004) Isolated acetabular polyethylene exchange through the anterolateral approach. J Arthroplasty 19(4):498-500 